\title{
Correlation of B-Type Natriuretic Peptide Level with Severity of Coronary Artery Disease in Non St Elevated Acute Coronary Syndrome with Normal Left Ventricular Function
}

SOHEL MAHMUD ${ }^{1}$, AKM. FAZLUR RAHMAN ${ }^{1}$, S.M. AHSAN HABIB ${ }^{1}$, CHAUDHURY MESHKAT AHMED ${ }^{1}$, S.M. MUSTAFA ZAMAN ${ }^{1}$. MOLLAH EMDADUL HAQUE ${ }^{2}$, KHANDER AISHA SIDDIKA ${ }^{3}$, HIRONMOY DAS ${ }^{4}$, MD. SHAMIM AHASAN ${ }^{5}$, MD. ARIF HOSSAIN ${ }^{3}$, MOHAMMAD ZAKIR HOSSAIN ${ }^{6}$

${ }^{1}$ Department of Cardiology, Bangabandhu Sheikh Mujib Medical University (BSMMU), Dhaka, ${ }^{2}$ Department of Cardiology, Khulna Medical College, Khulna, ${ }^{3}$ Department of Cardiolgy, National Institute of Cardiovascular Diseases, Dhaka, ${ }^{4}$ Department of Cardiolgy, Sylhet Osmani Medical College, Sylhet, ${ }^{5}$ Gopal gonj Sadar Hospital, Gopalganj, ${ }^{6}$ Upazila Health Complex, Keraniganj, Dhaka

Address of Correspondence: Dr. Sohel Mahmud, Consultant, Department of Cardiology, Bangabandhu Sheikh Mujib Medical University, Shahbag, Dhaka.E-mail: sohel.mahmud75@yahoo.com

\begin{abstract}
:
Background: Coronary artery disease (CAD) is predicted to be the most common cause of death and disability globally by 2020. In Bangladesh, for better management of coronary artery disease and to reduce the burden of acute coronary events patients with non ST elevated acute coronary syndrome (NSTE-ACS) should be focused. $B$-type natriuretic peptide (BNP) can be suggested as a tool to predict severity of coronary atherosclerotic lesion even with normal left ventricular $(L V)$ function and thus to categorize the patients for appropriate referral and invasive evaluation. Aims: This study is designed to assess the relationship between level of BNP and severity of coronary artery disease assessed with SYNTAX score in NSTE-ACS patients with normal LV function. Methods: This cross sectional observational study was conducted at UCC, BSMMU during the period of May 2014 to April 2015 among the patients with non ST elevated myocardial infarction (NSTEMI) and unstable angina. 116 patients were enrolled by non-random purposive sampling who was admitted for coronary angiogram. All the data were recorded in structured questionnaire including details of medical history, coronary risk factors and physical findings. In NSTE-ACS patients with normal LV function venous blood samples were collected for BNP and later SYNTAX scoring was assessed during coronary angiogram. The relationship between level of BNP and SYNTAX score in patients with both UA and NSTE-MI was assessed statistically to evaluate the validity of BNP as a tool to predict severity of coronary atherosclerotic lesions among the patients with NSTE-ACS. Results: The mean age was $57.84 \pm 8.82$ years. Among the 116 patients, highest frequency of patients was in the age group 51-60 years 55(47.4\%). In which 88(75.9\%) were male. Male:Female ratio is 3.1:1. The percentage of risk factors was higher in NSTEMI group and difference with UA was statistically significant ( $<0.05)$. Serum BNP in UA 64.9 \pm 13.07 and in NSTEMI 107.2 \pm 11.53 . The mean difference of serum BNP between two groups is statistically significant. In UA group the SYNTAX score was found 13.2 \pm 11.1 and in NSTEMI 19.9 \pm 13.5 which is statistically significant. In UA group maximum patients were found two vessel disease and in NSTEMI maximum patients in three vessel disease. $70.0 \%$ of patients of three vessel disease had e" $80 \mathrm{pg} / \mathrm{ml}$ of BNP. The association is statistically significant $(p<0.05)$. Higher the level of BNP reflect higher the vessel involvement and SYNTAX score irrespective of UA and NSTEMI. Conclusion: Our study reveals BNP is a candidate for entry into the setting of principal risk scores. Our findings indicate that the level of BNP may reflect the severity of ischemic insult even when irreversible injury and systolic dysfunction have not occurred.
\end{abstract}

Introduction:

Acute coronary syndrome (ACS) remain a leading cause of morbidity and mortality. In Bangladesh the age adjusted (20-69y) prevalence of coronary heart disease(CHD) was 1.85 with $95 \% \mathrm{CI}^{1}$. These patients are not only prone to develop complications during the acute phase, but also experience higher risk of death \& recurring major acute cardiovascular events after discharge. So risk stratification strategies have emerged to help select the most effective approach of treatment.

B-type natriuretic peptide (BNP) is a peptide consisting of 32 amino acids produced by the myocytes as a pro hormone. It is released in response to ventricular dilatation 
and pressure overload, in its active form after peptidase degradation, into the cardiovascular system ${ }^{2}$.

Recently it has been demonstrated that BNP and $\mathrm{N}$-terminal pro-B-type natriuretic peptide (NT pro-BNP) also provide predictive information on Non ST elevated acute coronary syndromes (NSTE-ACSs) and they appear related to the severity of CAD in patients affected with Non ST elevated ACS $^{3}$.The first published study was by de Lemos et al (2001).They showed that the 10 month mortality increased with increasing levels of BNP, with a mortality of approximately $1 \%$ in the lowest quartile and $7-15 \%$ in the highest quartile in NSTE-ACS patient. Later, the same research group validated these findings in another study, including 1676 patients with unstable CAD. In that study, a prospectively defined decision-limit of $80 \mathrm{ng} / \mathrm{L}$ was able to identify a group of patients with a 30 -day and 6months mortality of $5.0 \%$ and $8.4 \%$, respectively, compared to $1.2 \%$ and $1.8 \%$ in the group with lower levels of BNP. BNP was also associated to the risk of subsequent $\mathrm{CHF}$, whereas there was no significant association to the risk of future MI.

BNP and pro-BNP could be indicators for multi vessel disease, poor TIMI flow as well as markers of coronary disease extension. In OPUS-TIMI-16 trial, elevated BNP measured at a mean time of $40 \pm 20 \mathrm{~h}$ after the onset of symptoms was associated with a high risk of death, myocardial infarction, and heart failure at 30 days and 10months.

This association remained significant for the subgroup of patients with UA/NSTEMI. Furthermore, after adjustment for other independent predictors of the long-term risk of death, BNP $>80 \mathrm{pg} / \mathrm{ml}$ was significantly associated with increased mortality at 10 months. Moreover, patients with BNP $>80 \mathrm{pg} / \mathrm{ml}$ were also at a high risk of new or progressive heart failure, as compared with patients with BNP d" $80 \mathrm{pg} / \mathrm{ml}$. In the TACTICS-TIMI-18 trial, UA/ NSTEMI patients with BNP $>80 \mathrm{pg} / \mathrm{ml}$ at enrollment had a higher mortality at seven days and six months. The association between elevated BNP and increased mortality was independent of other important clinical predictors, including elevated troponin I and heart failure or LV ejection function.

Before that a few studies has been done but they are limited by their retrospective nature not having information about LV functions. Because of different clinical presentations, coronary syndromes without ST- elevation encompass a wide range of events and have different prognostic values in relation to the type of plaque lesions and the diffusion of coronary atherosclerosis. The risk assessment, based on clinical history and examination, electrocardiographic (ECG) characteristics, and markers of myocardial damage, still remains relatively inaccurate ${ }^{4}$.

However, the strong association between levels of BNP and NT-proBNP and mortality even among patients without myocyte necrosis (as detected by the release of cardiac troponin) indicate that the level of BNP may reflect the severity of the ischemic insult, even when irreversible injury has not occurred ${ }^{5}$. In this study, we were correlate the level of BNP with extent and severity of CAD in non ST elevated acute coronary syndrome (NSTE-ACS) patients by using SYNTEX score.

\section{Aim of the Study:}

To correlate BNP level with angiographic severity of coronary artery disease assessed by SYNTEX score in Non-ST elevated acute coronary syndrome with normal LV function.

\section{Material and Methods:}

\section{Study Population:}

This cross sectional observational study was performed on the 116 consecutive subjects who were presenting to the cardiology department of University Cardiac Center of BSMMU with unstable angina and non-ST elevated myocardial infarction with normal LV function during the study period from May 2014 to April 2015.

Exclusion criteria: Patients with a history of myocardial infarction, ST elevation on admission ECG, Patients with stable angina pectoris, ECG showing new LBBB or new Q waves, Patients taking drugs like diuretics, ACEI, ARBs, B-blocker, Patients with valvular heart disease, acute or chronic heart failure, cardiomyopathy, systolic dysfunction with ejection fraction $<50 \%$, renal, liver, neoplastic, inflammatory and infectious diseases were excluded.

\section{Study Procedure:}

All the patients who were presented with ACS with no ST elevation and underwent coronary angiography attending the study place during the study period were enrolled in the study following inclusion and exclusion criteria by consecutive non random sampling.

Patients were evaluated prior to blood sampling to assess their heart failure status according to the New York Heart Association. All recruited patients underwent echocardiographic examination(Vivid-7; GE Vingmed Sound, Horten, Norway) with a $2.5-3.5 \mathrm{MHz}$ transducer to evaluate wall motion abnormality, ventricular morphology and systolic functions ${ }^{6}$ (Schiller, Shah, Crawford, et al. 1989). 


\section{Evaluation of left ventricular function:}

Following parameters were considered for assessment of left ventricular function by echocardiography:

o Ventricular end-diastolic dimension: 37 to $56 \mathrm{~mm}$.

o Ventricular end-systolic dimension : 26 to $36 \mathrm{~mm}$

o Ejection fraction: 50 to $70 \%$

\section{Laboratory assays}

Plasma BNP and Troponin-I was immediately analyze on the same EDTA-anti-coagulated blood sample collected on admission using the quantitative immune fluorescence assay manufactured by Biosite (San Diego, CA, USA). The analytic sensitivity of the BNP assay is $<5 \mathrm{pg} / \mathrm{ml}$ and for Troponin-I is $<0.1 \mathrm{ng} / \mathrm{ml}$.

\section{SYNTAX Score and Angiographic analysis}

All patients were undergone selective coronary angiography with the Judkins technique using the Siemens Angioscop X-ray (Siemens Artis zee; Siemens Healtcare, Muenchen, Germany) by physicians who were blinded to the patient's clinical or BNP status.

Coronary stenosis was quantified using validated quantitative coronary angiography by the consensus opinion of two experienced interventional cardiologists with $>50 \%$ diameter stenosis considered as significant. Assessment of epicardial coronary flow was did using the TIMI flow grade according to established methods ${ }^{7}$. All coronary angiograms were evaluated according to the SYNTAX score (SS) which is a novel anatomical tool characterizing coronary vasculature. It grades the complexity of coronary artery disease and does not consider lesion treatment ${ }^{8}$. The SYNTAX score is the sum of the points assigned to each individual lesion identified in the coronary tree with $>50 \%$ diameter narrowing in vessels of $>1.5 \mathrm{~mm}$ diameter. The coronary tree is divided into 16 segments according to the AHA classification.

Each segment is given a score of 1 or 2 based on the presence of disease and this score is then weighted based on a chart, with values ranging from 3.5 for the proximal left anterior descending artery (LAD) to 5.0 for left main, and 0.5 for smaller branches.

All angiographic variables pertinent to SS calculation were computed by interventional cardiologists on diagnostic angiograms obtained before the procedure. The final score were calculated on a patient basis from the individual lesion scores, which was saved in a dedicated database.

The CAD patients were categorized into tertiles on the basis of SS, and the SS tertiles were defined as low
SYNTAX scores are d"22, intermediate SYNTAX scores range from 23 to 32 and high SYNTAX scores are $>32$ (2014 ESC/EACTS Guidelines on myocardial revascularization). High scores are associated with increasing cardiac mortality, major adverse cardiac events, and a specific, predefined combination of end points ${ }^{7}$.

\section{Statistical Analysis:}

The statistical analysis was performed using the SPSS software for Windows, version 22.0 (SPSS, Inc., Chicago). Summary statistics for continuous variables were recorded as the mean $+\mathrm{SD}$ and the categorical data were summarized as frequencies and percentages. Correlations between continuous variables were calculated according to Pearson's correlation coefficient. Logistic regression analysis was performed with the extent of CAD and degree of SYNTAX score, smoking, diabetes, hypertension and dyslipidemia as the dependent variable and BNP level as independent variable. Unpaired Student t- test was used for continuous variable and chi-square test for qualitative variables. $\mathrm{P}$ value of less than 0.05 was considered statistically significant.

\section{Results \& Observation:}

This cross-sectional observational study was conducted in the University Cardiac Center, Bangabandhu Sheikh Mujib Medical University, Dhaka, over a period of one year from May 2014 to April 2015. The main objective of the study was to correlate the BNP level with angiographic severity of coronary artery disease by SYNTAX score in Non-ST elevated acute coronary syndrome with normal LV function. A total of 116 adult patients who had presenting to the cardiology department of University Cardiac Center of BSMMU with Non ST elevated ACS during the study period were included in this study.

The mean age was $57.84 \pm 8.82$ years. Among the 116 patients, highest frequency of patients was in the age group 51-60 years 55(47.4\%). Out of 116 respondents, $88(75.9 \%)$ were male and $28(24.1 \%)$ were female. Male: Female ratio is 3.1:1. In risk factors of the patients, the percentage was higher in NSTEMI group and difference with UA was statistically significant $(\mathrm{p}<0.05)$.

In comparison with SYNTAX score and BNP level, higher percentage $88.4 \%$ of patients with BNP level below $80 \mathrm{pg} /$ $\mathrm{ml}$ and $10.0 \%$ patients of $>80 \mathrm{pg} / \mathrm{ml}$ of BNP had low SYNTAX score $(\leq 22)$.

In comparison of BNP level in UA and NSTEMI patients, most of the patients (84.1\%) had below $80 \mathrm{pg} / \mathrm{ml}$ of BNP and $15.9 \%$ above $80 \mathrm{pg} / \mathrm{ml}$ of BNP in UA. $62.3 \%$ patients had $<80 \mathrm{pg} / \mathrm{ml}$ of BNP and $37.7 \%$ above $80 \mathrm{pg} / \mathrm{ml}$ of BNP in 
NSTEMI group. The percentage was higher in UA and the difference was statistically significant $(\mathrm{p}<0.05)$.

Multiple logistic regression analysis showed that only SYNTAX score were only variable found to be statistically significant $(\mathrm{OR}=1.654, \mathrm{p}=0.002)$.

SYNTAX score showed positive correlation $(\mathrm{r}=+0.670)$ with BNP in UA, which is statistically significant.
Pearson's correlation coefficient (r) test was performed to compare relationship between SYNTAX score with BNP. The test of significance was calculated and $p$ value $<0.05$ was accepted as level of significance.

SYNTAX score showed positive correlation $(\mathrm{r}=+0.670)$ with BNP in UA and NSTEMI group, which is statistically significant.

Table-I

Demographic characteristics of the patients $(n=116)$

\begin{tabular}{|c|c|c|}
\hline Demographic characteristics & Frequency & Percentage $(\%)$ \\
\hline \multicolumn{3}{|l|}{ Age in years } \\
\hline $30-40$ & 17 & 14.7 \\
\hline $41-50$ & 27 & 23.3 \\
\hline $51-60$ & 55 & 47.4 \\
\hline$>60$ & 17 & 14.7 \\
\hline Total & 116 & 100.0 \\
\hline Mean \pm SD (yrs) & $57.84 \pm 8.82$ & \\
\hline Range & $(31-69)$ yrs & \\
\hline \multicolumn{3}{|l|}{ Sex } \\
\hline Male & 88 & 75.9 \\
\hline Female & 28 & 24.1 \\
\hline Total & 116 & 100.0 \\
\hline
\end{tabular}

$\mathrm{n}=$ Number of subjects, $\%=$ Percentage of frequency in each group

Table-II

Comparison of risk factors of the patients in two groups $(n=116)$

\begin{tabular}{lcccc}
\hline Risk factors & UA $(\mathrm{n}=63)$ & NSTEMI $(\mathrm{n}=53)$ & Total $(\mathrm{n}=116)$ \\
No. $(\%)$ & p value \\
\hline Diabetes mellitus & No. $(\%)$ & $31(58.5 \%)$ & $55(47.4 \%)$ & $0.028^{*}$ \\
Hypertension & $24(38.1 \%)$ & $38(71.7 \%)$ & $66(56.9 \%)$ & $0.003^{*}$ \\
Smoking & $28(44.4 \%)$ & $33(62.3 \%)$ & $60(51.7 \%)$ & $0.037^{*}$ \\
Dyslipidemia & $27(42.9 \%)$ & $28(52.8 \%)$ & $49(42.2 \%)$ & $0.034^{*}$ \\
Family history of CAD & $21(33.3 \%)$ & $27(50.9 \%)$ & $43(37.1 \%)$ & $0.005^{*}$ \\
\hline
\end{tabular}

* = Significant. $\mathrm{p}$ values $<0.05$ was accepted as level of significance.

Table-III

Comparison between SYNTAX score and level of BNP $(n=116)$

\begin{tabular}{|c|c|c|c|c|}
\hline \multirow[t]{2}{*}{$\overline{\text { SYNTAX score }}$} & \multicolumn{2}{|c|}{ Level of BNP } & \multirow{2}{*}{$\begin{array}{c}\text { Total } \\
(\mathrm{n}=116) \\
\text { No. }(\%)\end{array}$} & \multirow[t]{2}{*}{$\mathrm{p}$ value } \\
\hline & $\begin{array}{c}<80 \mathrm{pg} / \mathrm{ml} \\
(\mathrm{n}=86) \\
\text { No. }(\%)\end{array}$ & $\begin{array}{c}>80 \mathrm{pg} / \mathrm{ml} \\
(\mathrm{n}=30) \\
\text { No. }(\%)\end{array}$ & & \\
\hline Low SYNTAX score $(\leq 22)$ & $76(88.4 \%)$ & $3(10.0 \%)$ & $79(68.1 \%)$ & $<0.001^{*}$ \\
\hline Intermediate SYNTAX score (23-32) & $10(11.6 \%)$ & $8(26.7 \%)$ & $18(15.5 \%)$ & \\
\hline High SYNTAX score $(\geq 33)$ & 0 & $19(63.3 \%)$ & $19(16.4 \%)$ & \\
\hline Total & $86(100.0 \%)$ & $30(100 \%)$ & $116(100 \%)$ & \\
\hline
\end{tabular}

Data were expressed as frequency and percentage. Statistical analysis were done by Chi-square test was performed to compare between groups. $\mathrm{P}$ values $<0.05$ was accepted as level of significance. $\mathrm{n}=$ Number of patients $*=$ Significant 
Table-IV

Comparison of level of BNP in two groups $(n=116)$

\begin{tabular}{lcccc}
\hline BNP level & UA $(\mathrm{n}=63)$ & NSTEMI $(\mathrm{n}=53)$ & Total $(\mathrm{n}=116)$ & $\mathrm{p}$ value \\
& No. $(\%)$ & No. $(\%)$ & No. $(\%)$ & \\
\hline$<80 \mathrm{pg} / \mathrm{ml}$ & $53(84.1 \%)$ & $33(62.3 \%$ & $86(74.1 \%)$ & $0.007^{*}$ \\
$>80 \mathrm{pg} / \mathrm{ml}$ & $10(15.9 \%)$ & $20(37.7 \%)$ & $30(25.9 \%)$ & \\
\hline Total & $63(100.0 \%)$ & $53(100.0 \%)$ & $116(100.0 \%)$ & \\
\hline
\end{tabular}

Data were expressed as frequency and percentage. Statistical analysis were done by Chi-square test was performed to compare between groups. $\mathrm{P}$ values $<0.05$ was accepted as level of significance. $\mathrm{n}=$ Number of patients $*=$ Significant

\section{Table-V}

Multiple logistic regression analysis using serum BNP level as dependent variable $(n=116)$.

\begin{tabular}{lccc}
\hline Variables & S.E. & Sig. & Odd ratio \\
\hline Hypertension & 1.355 & 0.295 & 4.133 \\
Smoking & 1.288 & 0.288 & 0.254 \\
Dyslipidemia & 1.768 & 0.386 & 0.216 \\
Glycemic status & 2.11 & 0.31 & 8.543 \\
Syntax score & 0.159 & 0.002 & 1.654 \\
\hline
\end{tabular}

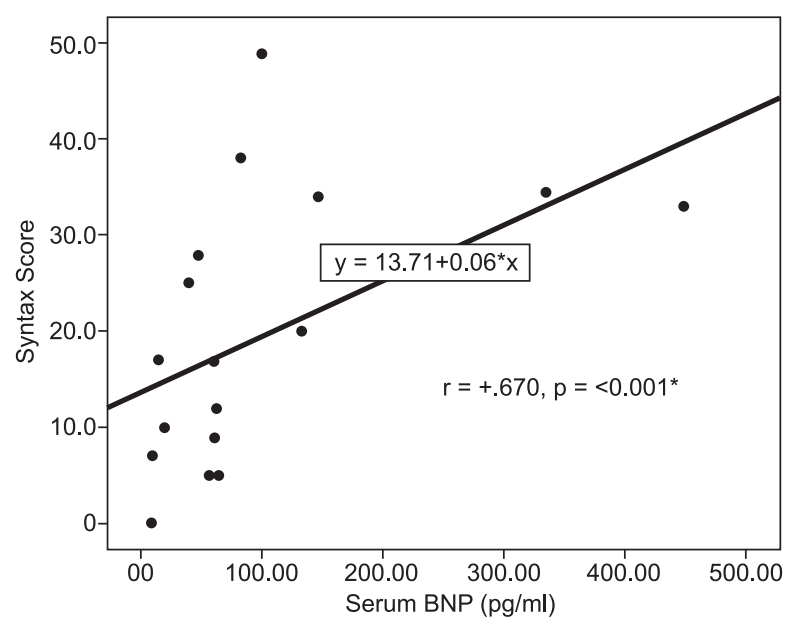

Fig.-1: Correlation between serum BNP and SYNTAX score in $U A(n=63)$

* Significant

Pearson's correlation coefficient ( $\mathrm{r}$ ) test was performed to compare relationship between SYNTAX score with BNP. The test of significance was calculated and $p$ value $<0.05$ was accepted as level of significance.

\section{Discussion:}

The aim of the study was to correlate of BNP level with angiographic severity of coronary artery disease in NonST elevated acute coronary syndrome with normal LV function. This study included 116 patients out of them 63 patients had UA another 53 patients had NSTEMI.

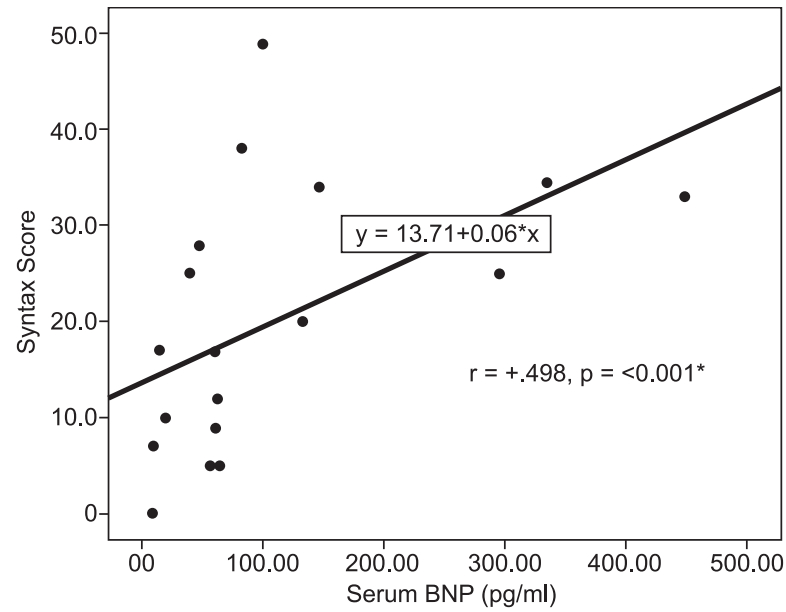

Fig.-2: Correlation between serum BNP and SYNTAX score in NSTEMI $(n=53)$.

* Significant

The mean age was $57.84 \pm 8.82$ years. Among the 116 patients, highest frequency of patients was in the age group 51-60 years 55(47.4\%) followed by $41-50$ years $27(23.3 \%)$. Out of 116 respondents, $88(75.9 \%)$ were male and $28(24.1 \%)$ were female. Male: Female ratio is 3.1:1. Our observation is similar with Mahmoud et $\mathrm{al}^{9}$. (2013) and Sadanandan et al..$^{10}(2004)$. They study included 58 patients with NSTEMI "Group I" (72.5\%) and 22 individuals as a control "Group II" (27.5\%), 31 males and 27 females. The mean age was $55.3 \pm 11.06$ years. Sadanandan et al. (2004) reported mean age was $61.2 \pm 22$ and male $67 \%$. 
In present the percentage of risk factors was higher in NSTEMI group and difference with UA was statistically significant $(\mathrm{p}<0.05)$. This findings are consistent with the study of Vellani et al. (2013).

BNP levels were significantly higher in the NSTEMI group in comparison to the UA group (107.2 \pm 11.5 vs $64.9 \pm 13.1$ $\mathrm{pg} / \mathrm{mL} ; \mathrm{p}<0.001)$. BNP $>80 \mathrm{pg} / \mathrm{mL}$ was recruited in 20 of 53 (37.7\%) patients of NSTEMI while 10 of 63 (15.9\%) of UA patients were recruited. Triple vessel disease was revealed more frequently in patients with BNP $>80 \mathrm{pg} / \mathrm{mL}$. 21 out of $32(70 \%)$ patients of Triple vessel disease had BNP $>80$ $\mathrm{pg} / \mathrm{ml}$. The main finding of our study is that BNP levels are related also to the severity of coronary atherosclerosis. Patients with multi-vessel disease showed higher BNP levels than subjects with only one or two vessel involvement. This trend was confirmed independently of the diagnosis of UA or NSTEMI. Our results are in accordance with those of Sadanandan et $\mathrm{l}^{10}$. (2004) showing a correlation between vessel involvement and BNP levels.

Again, we demonstrated that BNP threshold of $80 \mathrm{pg} / \mathrm{ml}$ appears able to predict the extension of coronary disease independently from LV systolic dysfunction and enlargement. The same value has been previously recognized by Morrow et al. ${ }^{11}$ (2003) and Sadanandan et al. ${ }^{10}$ (2004). Our results are also in accordance with study by Alberto Palazzuoli et al ${ }^{12}(2011)$ but the cited study was retrospective in nature.

In our study showed the comparison between SYNTAX score and BNP level in which $88.4 \%$ of UA patient had low SYNTAX score with BNP level below $80 \mathrm{pg} / \mathrm{ml}$. On the other hand high SYNTAX group had BNP level $>80 \mathrm{pg} / \mathrm{ml}$ which was found in $63.3 \%$ of NSTEMI patients. The difference of percentage is statistically significant $(p<0.05)$. Similar findings was observed by Mahmoud et $\mathrm{al}^{9}$. (2013)

Most importantly our study strongly showed that high $\mathrm{BNP}(>80 \mathrm{pg} / \mathrm{ml})$ is a strong predictor of high SYNTAX score and triple vessel disease irrespective of diagnosis of UA or NSTEMI. Our study were correlate with Sadanandan et al ${ }^{10}$ (2004); Goyal et al. ${ }^{13}$ (2014), Mahmoud et al. ${ }^{9}$ (2013).

All together these data could explain the mechanisms linking BNP to an adverse outcome in CAD, it represents a marker of coronary disease severity. For the above mentioned reasons BNP should be considered as an indicator of extend and severity of coronary artery disease.

\section{Conclusion:}

From the results of this study we observed that there is positive correlation of serum BNP with SYNTAX score. So, it may be concluded that serum BNP level reflect the severity of coronary artery disease in non-ST elevated acute coronary syndrome patients with normal left ventricular function.

\section{Reference:}

1. Sayeed, MA, Hajera, Mahtab, Shurovi, Sayeed, Tanjima, Begum, Parvinakter, Khanam, Akter, Banu, 2001, 'Prevalence and risk factors of coronary heart disease in a rural population of Bangladesh, Ibrahim Med. Coll, vol. 4, no. 2, pp. 37-43.

2. Levin, ER, Gardner, DG, Samson, WK. 1998, 'Natriuretic peptides [Review]'. N Engl J Med. vol. 339, pp. 321e328.

3. de Lemos JA, Morrow DA, Bentley JH, et al. 2001, 'The prognostic value of B-type natriuretic peptide in patients with acute coronary syndromes'. $N$ Engl J Med. vol. 345, pp. $1014 \mathrm{e} 1021$.

4. Antman, EM, Cohen, M, Bernink, PJ, et al. 2000, 'The TIMI risk score for unstable angina/non ST elevation MI: a method for prognostication and therapeutic decision making'. JAMA. vol. 284, pp. 835-842.

5. Morrow, DA, De, Lemos, JA, Sabatine, MS, et al. 2003, 'Evaluation of B type natriuretic peptide for risk assessment in unstable angina/non-ST elevation myocardial infarction'. J Am CollCardiol. vol.41 pp. 1264-1272.

6. Schiller, NB, Shah, PN, Crawford, M, et al. 1989, 'Recommendations for quantification of the left ventricle by two- dimension echocardiography'. J Am SocEchocardiogr. vol. 2, pp. 358-367.

7. Gibson, CM, Ryan, KA, Kelley, M, et al. 1999, 'Methodological drift in the assessment of TIMI grade 3 flow and its implications with respect to the reporting of angiographic trial results. The TIMI Study Group'.Am Heart $J$. vol. 137, pp. $1179 \mathrm{e} 1184$.

8. Friedrich, W, Mohr, Garg, S, et al. 2008, 'The SYNTAX Trial: synergy between PCI with TAXUS and cardiac surgery. vol. 5, pp. 33-39.

9. Mahmoud, KS, Ibrahem, AM, Saad, M, Awny, M, 2013, 'Relation between serum B-type brain natriuretic peptide level and complexity \& severity of coronary artery disease in nonST elevation myocardial infarction', The Egyptian Heart Journal, vol. 30, pp. 1-5.

10. Sadanandan, S, Annon, CP, Chekuri, K, Murphy, SA, Dibattiste, PM, Morrow, DA et al. 2004, 'Association of elevated Btype natriuretic peptide levels with angiographic findings among patients with unstable angina and non-ST segment elevation myocardial infarction', The Journal of American College of Cardiololgy, vol. 44, no. 3, pp. 564-8.

11. Morrow, DA, De, Lemos, JA, Sabatine, MS, et al. 2003, 'Evaluation of B type natriuretic peptide for risk assessment in unstable angina/non-ST elevation myocardial infarction'. J Am CollCardiol. vol.41 pp. 1264-1272.

12. Palazzuoli, Alberto, Maisel, Alan, Caputo, Maria, et al. 2011, 'B-type natriuretic peptide levels predict extent and severity of coronary disease in non-ST elevation coronary syndromes and normal left ventricular systolic function'. Regulept. vol. 167, pp. 129-133.

13. Goyal, BM, Sharma, SM, Walia, M, 2014, 'B-Type natriuretic peptide levels predict extent and severity of coronary artery disease in non-ST elevation acute coronary syndrome and normal left ventricular function', Indian Heart Journal, vol. 66, pp. 183-187. 